J. Segundo-Ramirez, A. Bayo-Salas, M. Esparza, J. Beerten and P. Gómez, "Frequency Domain Methods for Accuracy Assessment of Wideband Models in Electromagnetic Transient Stability Studies," IEEE Transactions on Power Delivery, early access.

Digital Object Identifier: 10.1109/TPWRD.2019.2927171

URL:

http://ieeexplore.ieee.org/stamp/stamp.jsp?tp=\&arnumber $=8758887$

(C) 2019 IEEE. Personal use of this material is permitted. Permission from IEEE must be obtained for all other users, including reprinting/ republishing this material for advertising or promotional purposes, creating new collective works for resale or redistribution to servers or lists, or reuse of any copyrighted components of this work in other works. 


\title{
Frequency Domain Methods for Accuracy Assessment of Wideband Models in Electromagnetic Transient Stability Studies
}

\author{
IEEE-PES Task Force on Frequency Domain Methods for Electromagnetic Transient Studies \\ Chairman: Pablo Gómez \\ Contributors: Juan Segundo-Ramirez, Member, IEEE, Alejandro Bayo-Salas, Member, IEEE, \\ Miguel Esparza, Member, IEEE, Jef Beerten, Member, IEEE, Pablo Gómez, Senior Member, IEEE
}

\begin{abstract}
Modern power systems face several problems at frequencies above the range of traditional stability studies due to the increasing penetration of power electronic devices. This phenomenon has been recently referred to as electromagnetic transient stability and is a growing issue in systems with power electronic converters at any power and voltage level, such as FACTS, HVDC, interfaces for grid connection of renewable energies, custom power devices for power quality enhancement, among others. The study of power systems stability is usually carried out by simulation tools that represent the power system through phasor models. However, due to the faster dynamics of modern systems, the harmonic interaction among the controllers, the converters, and the electric power components, recent research results suggest that some stability analysis should be conducted with models suitable for wider frequency ranges, e.g., electromagnetic transient models. This paper reviews the use of frequency domain methods to analyze the influence of the modeling approach of passive power components on the results of electromagnetic transient stability studies.
\end{abstract}

Index Terms-Electromagnetic transients, power system harmonics, power system stability, wideband modeling.

\section{INTRODUCTION}

$\mathrm{E}$ LECTROMAGNETIC transient (EMT) models are commonly used for accurate representation of electric power components or systems subject to switching operations, lightning phenomena or fault conditions [1]. On the other hand, low bandwidth models with lumped-parameter components are preferred for steady-state or quasi-steady-state analysis. However, some phenomena, overlooked by these lumpedparameter models, arise in harmonically distorted power systems with nonlinear components, frequency-dependent elements, power electronic converters, and closed-loop controllers [2]. Examples of these power systems are power electronically-controlled microgrids, high-voltage DC (HVDC) systems, power electronic interfaced wind power and photovoltaic plants, and practically any power-electronic-based power system.

J. Segundo-Ramirez is with the School of Engineering, Universidad Autónoma de San Luis Potosi, SLP 78290, Mexico (e-mail: juan.segundo@uaslp.mx)

A. Bayo-Salas and J. Beerten are with the Department of Electrical Engineering of KU Leuven, Leuven 3001, Belgium (e-mail: jef.beerten@esat.kuleuven.be).
In particular, voltage source converters (VSC) present: (i) faster dynamics and control loops extended to a broader and higher range of frequencies compared to conventional installations, and (ii) generation of harmonics in a wider spectrum and extended to higher frequencies compared to thyristor-based converters. Consequently, converter dynamics and harmonics interact with the dynamic behavior of the AC network at such frequencies, which is mostly determined by the network resonances.

The new interactions have given rise to new phenomena, which was previously unexpected. Regarding power quality, the new harmonic generation patterns have triggered the analysis of supra-harmonics [3] and recommendations for the modeling of components. Concerning power system stability, the new dynamic interactions have led to a new stability problem currently known as harmonic or electromagnetic transient stability.

The first problems at the high-voltage level have been recently experienced in the first worldwide installations of VSC-HVDC in offshore wind farms [4] and point-to-point DC links embedded in the power system [5]-[7]. In these particular cases, instabilities appeared at frequencies between 400 and $1700 \mathrm{~Hz}$. Besides the previous problems, harmonic interactions have also been experienced previously in traction networks [8], [9] and distribution systems [10].

The shift of dynamic and power quality phenomena towards higher frequencies challenges the traditional methodologies used in both stability and harmonic studies. In particular, stability studies have extensively made use of phasor-based models and algebraic equations to represent the AC network [11]-[14]. On the other hand, harmonic studies traditionally use lumped-parameter models to represent transmission lines in the frequency range of interest and harmonic load flows to analyze the grid distortion [15]. Indeed, if the possible problems shift to higher frequencies, previous methodologies and representations loose accuracy to capture the actual phenomena and may lead to misleading results.

\footnotetext{
Miguel Esparza is with Delee Technologies Mexico, Monterrey, NL 64810, Mexico (e-mail: miguel.esparza@delee.bio).

P. Gómez is with the Electrical and Computer Engineering Department of Western Michigan University, 1903 W Michigan Ave., Kalamazoo, MI 490085329, USA (e-mail: pablo.gomez@wmich.edu).
} 
This paper presents an in-depth review, analysis, and discussion of the state-of-the-art on frequency domain methods to analyze the influence of the modeling approach of passive power components for electromagnetic transient stability studies. The paper is organized as follows: Section II presents a review of relevant concepts and definitions. Section III presents a literature review of reported problems and studies related to this topic. Section IV presents the application areas in which phasor-based models or frequency-independent models may lead to an inaccurate representation of the problems under consideration. Besides, some guidelines to identify phenomena that require wideband models for stability studies are provided. Section V presents a brief description of frequency domain methods for the study of electromagnetic transient stability. Section VI illustrates the application of the methods previously described in a test case corresponding to the electromagnetic interaction between a voltage source converter (VSC) and an AC network. Finally, Section VII provides the final conclusions of this paper.

\section{DEFINITIONS}

The modeling approaches for transient stability, small signal stability, voltage stability, dynamic stability, electromechanical transients, subsynchronous resonance, among other phenomena, go from algebraic models to hybrid models, depending on the required level of detail [11]-[14], [16]. In general, low-frequency range models are used for these purposes since slow dynamic interactions and low-frequency excitations are expected. On the other hand, wideband models are used for electromagnetic transients since frequencies up to $1 \mathrm{MHz}$ or even higher are commonly involved in this type of studies [17].

In modern electric systems, a wide range of frequencies are present even in stationary and quasi-stationary state due to the high penetration of power electronic converters. According to previous research [18]-[21], harmonic stability problems are caused by interactions between closed-loop controllers and passive network components, either at a harmonic frequency or at any other frequency component different from the fundamental frequency. This problem is commonly present in power electronic-based AC, DC, and hybrid systems, and can lead to the presence of uncharacteristic oscillations that significantly distort the waveforms and amplify some frequency components [22]. In some critical cases, this problem results in loss of stability [9]. Electromagnetic instability or harmonic instability is, therefore, the condition of non-equilibrium in which a natural frequency (resonance) of the network is excited because one or several installations are adversely controlling the energy in a system at a given spectrum. Consequently, the surplus of energy flowing into the circuit is transferred as an oscillation of the energy stored between electric and magnetic fields [23].

\section{LITERATURE REVIEW}

The problems associated with the presence of powerelectronic devices in power systems are gaining attention given the high penetration of FACTS, distributed generation units (DGUs), active filters, HVDC transmission, among others. Due to this trend, well-known undesirable harmonic effects such as increasing the equipment ratings [24]-[26] and losses [27][29], decreasing the equipment reliability [30], [31] and interference with the communication systems [3], among others, are becoming more critical in many different aspects of the system [32]. Most of the analyses performed on powerelectronic-based systems (e.g., stability, design, capacity planning, etc.) neglect or average the high switching frequencies of the power electronic devices to obtain timeinvariant models. However, traditional simplified models can misrepresent the actual behavior of networks with high penetration of power electronic devices [33]-[35], revealing the need of migrating to models with increased bandwidth able to properly consider high frequencies.

Modeling challenges of distributed generation (DG) based on renewable energies have been reported in [36]-[38]. Additionally, negative effects on the power quality of the grid have also been reported due to the generation of coupling harmonics [39] that could excite the resonances presented by the power network, passive elements, controllers, and loads [40]-[43]. Depending on the approach used to integrate the DG into the grid, different harmonic generation and propagation phenomena are manifested.

In multiple low-voltage DG units connected to a common distribution network (e.g., microgrids) [44], each DG unit injects harmonics to its point of common coupling (PCC). If two or more DG are connected to the same PCC or they are close enough, coupling harmonics among the sources will be generated [45]. Such coupling harmonics affect the performance and overall stability of the power-electronic-based system connected to the microgrid [43], [46], [47]. Under this operating condition, several non-ideal characteristics arise, such as a time-varying weak-grid equivalent [48] and unbalances [49], along with the coupling harmonics interaction. In addition, the controllers of grid-connected power-electronicbased systems become particularly complex to tune, since a third control loop for phase synchronization is usually required [50], [51].

For large-scale distributed power plants (LDPP) [52], [53], the harmonic propagation and resonances involved are quite different. Typically, clusters of DG are connected to a high voltage feeder through a distribution transformer. Under this approach, the capacitive couplings of the feeders and the transformer are the main source of resonances that could magnify some of the switching harmonics generated by the power-electronic devices [42]. The proposal of a detailed equivalent model that successfully represents the overall performance of the LDPP is still a challenge to address.

On a broader sense, the use of high-power electronic devices such as HVDC systems and FACTS presents operative and modeling challenges, despite their well-known benefits. Synchronous oscillations, harmonic resonances, poor system performance and undesired oscillatory phenomena have been reported in renewable systems connected through HVDC systems [54]-[56] due to the weak-grid equivalent and the 
interactions with the controllers and other HVDC systems [54]. For FACTS devices, research has mainly focused on the development of accurate models that allow the evaluation of their performance in large transmission networks [57]-[59].

Important efforts have been conducted on the analysis of harmonic stability for distribution networks [60], [61], offshore wind farms [54], [62], [63], HVDC converters embedded in an AC system [64]-[66], and HVDC links [67]-[70]. On these studies, the system stability was analyzed mainly by means of the impedance-based method. Instabilities were detected due to the interaction between converter control dynamics and network resonances. However, harmonic interactions with the power network are often overlooked since the network and the transmission lines are modeled by means of very simple models, such as equivalent inductance or conventional $\pi$ sections with constant lumped parameters.

Considering the above-mentioned problems and challenges reported in the literature, the development of wideband mathematical models able to consider the harmonic interactions generated in the switching process is of utmost importance to exploit the benefits offered by the high penetration of power electronic-based systems and to understand the high-frequency problems associated.

\section{NEED FOR WIDEBAND MODELING OF POWER SYSTEMS}

The interoperability between converters from different vendors is nowadays regarded as a key issue for future power systems [71], [72]. The integration of these converters in the network leads to interactions between different controllers and, in comparison with conventional systems, their dynamics and control loops are extended to a wider range of frequencies above the nominal frequency. As a result, converters also interact with the network's electromagnetic modes, commonly defined as resonances, which may lead to super-synchronous sustained oscillations or even instabilities. Such interactions give rise to stability problems in traction networks [8], [9] and distribution systems [10]. At the high-voltage level, the first worldwide installations of voltage-sourced converters (VSC)HVDC have experienced these problems in an HVDC connected offshore wind farm [4] and point-to-point DC links embedded in the power system [5]-[7]. The fact that this problem has rapidly affected the higher voltage level, once the first converters have been connected to it, is not a surprise; the inherent low damping and the increasing use of cables make the network prone to this type of instability.

Power system industry currently deems time-domain analysis as the most suitable way to analyze the interactions between multiple components and the stability of the system. This is driven by the fact that (i) the complexity in representing the important system dynamics have greatly increased with the integration of power-electronic components, (ii) their distributed nature requires the representation of a greater number of devices in comparison with systems with fewer and centralized conventional plants, and (iii) the confidentiality in their controls and parameters is imposed to protect the intellectual property of manufacturers. However, the detail in the modeling of the surrounding system often needs to be reduced to cope with the computational constraints in either offline tools or real-time simulation platforms. In addition, methods based on time-domain analysis cannot provide an overall and complete picture of the underlying interactions and the relative stability of the system given the inherent uncertainties of the network. For this reason, the use of frequency-domain methods as a complement to time-domain methods allows fully understanding the dynamics jeopardizing the system stability.

\section{FREQUENCY DOMAIN METHODS}

\section{A. Input impedance/admittance approach}

Considering each component of the network as a frequencydependent terminal impedance allows to estimate the resulting electromagnetic interactions between them. This approach is commonly known as impedance-based stability assessment. It was first used in the design of an input-filter for a regulated converter by Middlebrook et al. in the mid-70s [73], [74]. Since then, this input-output approach has been widely used to determine the stability in the interconnection of two subsystems in multiple fields or applications such as DC systems embedded in aeronautical applications [75]-[77], DC distribution networks [78], [79], or VSC-based systems [21], [80]. After the outages of the Swiss traction network due to excessive harmonic content [9], [81], [82], the approach of modelling the traction vehicle as an impedance became part of the standards of the Swiss Railways [83], [84] allowing to mathematically decouple the network infrastructure and the manufacturer's vehicle.

The input-admittance model is a way to represent and characterize the dynamic response of the converter for frequency-domain studies. The equivalent admittance of the VSC consists of a transfer function of the voltage at the PCC regarded as the input disturbance and the current as the controlled output. Therefore, this equivalent admittance characterizes the frequency-dependent response of the passive components and control loops as seen from the PCC. The attractiveness of this method in electrical networks is the direct link between an electrical impedance and a property of its stability: the passivity [85]. If the system exhibits a passive impedance, i.e., the impedance angle is bounded within $-90^{\circ}<$ $\varphi<90^{\circ}$, the system eigenmodes are damped and the system is stable. On the other hand, phases out of this boundary indicate non-passive regions where $\Re[Y(j \omega)]<0$, so that the system adds negative damping to the network and the eigenmodes become unstable if the other interconnected subsystem does not add enough damping.

Given an interconnected system as sketched in Fig. 1, the system response can be represented by the minor loop in (1) capturing the equivalent small-signal impedances of both systems.

$$
V_{\text {in }}(s)=V_{g}(s) \frac{1}{1+\frac{Z_{g}(s)}{Z_{\text {in }}(s)}}
$$




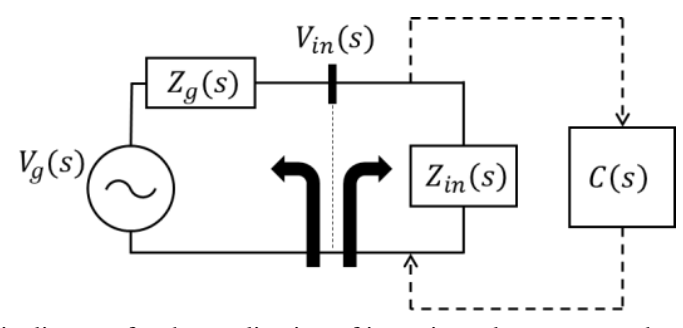

Fig. 1 Basic diagram for the application of input impedance approach.

This minor loop resembles the typical loop of a feedback system. Consequently, the criterion establishes the system stability analysis by the analysis of the minor loop defined by both impedances and the Nyquist stability criterion. Specifically, the interconnected system presents oscillatory behavior when the conditions in (2) and stability are analyzed based on the respective phase and gain margins.

$$
\begin{gathered}
\left|Z_{g}(s) / Z_{\text {in }}(s)\right|=1 \\
\angle Z_{g}(s) / Z_{\text {in }}(s)=-180^{\circ}
\end{gathered}
$$

Impedance models of converter and grid components can be obtained not only analytically, but also from EMT simulation tools or from measurements. This is one of the most important benefits of these methodologies.

\section{B. Extended Harmonic Domain}

The harmonic state space (HSS) was originally introduced by Wereley [86] in 1990 for modeling and analysis of linear periodic time-varying (LPTV) systems through linear timeinvariant (LTI) systems in the frequency domain. Several previous works have used this modeling approach for harmonic stability analysis [22], [87], [88]. A more recent approach, called extended harmonic domain (EHD) [89] was proposed in 2003 to represent in the time-frequency domain LPTV systems as LTI systems. This method is based on the Fourier series with dynamic complex coefficients, and unlike the HSS, it handles the time evolution of each harmonic component and is not limited to exponentially modulated periodic signals. Additionally, it handles nonlinearities through Toeplitz-matrixbased operations. Its mathematical formulation is briefly described next.

Consider the following $T$-periodic linear system,

$$
\begin{array}{r}
{\left[\begin{array}{c}
\dot{x}_{1}(t) \\
\vdots \\
\dot{x}_{N}(t)
\end{array}\right]=} \\
+\left[\begin{array}{ccc}
a_{1,1}(t) & \cdots & a_{1, N}(t) \\
\vdots & \ddots & \vdots \\
a_{N, 1}(t) & \cdots & a_{N, N}(t)
\end{array}\right]\left[\begin{array}{c}
x_{1}(t) \\
\vdots \\
x_{N}(t)
\end{array}\right] \\
+\left[\begin{array}{ccc}
b_{1,1}(t) & \cdots & b_{1, M}(t) \\
\vdots & \ddots & \vdots \\
b_{N, 1}(t) & \cdots & b_{N, M}(t)
\end{array}\right]\left[\begin{array}{c}
u_{1}(t) \\
\vdots \\
u_{M}(t)
\end{array}\right] \\
{\left[\begin{array}{c}
y_{1}(t) \\
\vdots \\
y_{S}(t)
\end{array}\right]=\left[\begin{array}{ccc}
c_{1,1}(t) & \cdots & c_{1, N}(t) \\
\vdots & \ddots & \vdots \\
c_{S, 1}(t) & \cdots & c_{S, N}(t)
\end{array}\right]\left[\begin{array}{c}
x_{1}(t) \\
\vdots \\
x_{N}(t)
\end{array}\right]} \\
+\left[\begin{array}{ccc}
d_{1,1}(t) & \cdots & d_{1, M}(t) \\
\vdots & \ddots & \vdots \\
d_{S, 1}(t) & \cdots & d_{S, M}(t)
\end{array}\right]\left[\begin{array}{c}
u_{1}(t) \\
\vdots \\
u_{M}(t)
\end{array}\right]
\end{array}
$$

System (3) can be regarded as the linearized version of a nonlinear switched periodic system; however, the nonlinearities can be handled without resorting to previous linearization if these can be expressed through Toeplitz-matrix based operations [90]. Since (3) is periodic, each state variable can be approximated through the Fourier series, for instance, the $r-$ th state variable using the complex Fourier series is,

$$
x_{r}(t) \approx \sum_{k=-h}^{h} X_{r\langle k\rangle}(t) e^{j k \omega_{0} t} \text { for } r=1,2, \ldots N
$$

Here, $X_{r\langle k\rangle}(t)$ represents the $k-$ th dynamic complex Fourier series coefficient of the $r$ - th state variable of (3), $\omega_{0}$ is the fundamental frequency in rad/s and is equal to $2 \pi / T$, where $T$ is the fundamental period in seconds, and $h$ is the highest harmonic considered in the approximation. Notice that if the time-domain variable $x_{r}(t)$ is $T$-periodic, then $X_{r\langle k\rangle}(t)$ will eventually settle to a constant value. Similarly, the timevarying elements of each matrix in (3) can also be approximated using the Fourier series and finally transform this LPTV system into an LTI system, as follows:

$$
\begin{gathered}
{\left[\begin{array}{c}
\dot{\mathbf{X}}_{1}(t) \\
\vdots \\
\dot{\mathbf{X}}_{N}(t)
\end{array}\right] \approx\left[\begin{array}{ccc}
\mathbf{a}_{1,1}-\mathcal{D} & \cdots & \mathbf{a}_{1, N} \\
\vdots & \ddots & \vdots \\
\mathbf{a}_{N, 1} & \cdots & \mathbf{a}_{N, N}-\mathcal{D}
\end{array}\right]\left[\begin{array}{c}
\mathbf{X}_{1}(t) \\
\vdots \\
\mathbf{X}_{N}(t)
\end{array}\right]} \\
+\left[\begin{array}{ccc}
\mathbf{b}_{1,1} & \cdots & \mathbf{b}_{1, M} \\
\vdots & \ddots & \vdots \\
\mathbf{b}_{N, 1} & \cdots & \mathbf{b}_{N, M}
\end{array}\right]\left[\begin{array}{c}
\mathbf{U}_{1} \\
\vdots \\
\mathbf{U}_{M}
\end{array}\right] \\
{\left[\begin{array}{c}
\mathbf{Y}_{1}(t) \\
\vdots \\
\mathbf{Y}_{S}(t)
\end{array}\right]=\left[\begin{array}{ccc}
\mathbf{c}_{1,1} & \cdots & \mathbf{c}_{1, \mathrm{~N}} \\
\vdots & \ddots & \vdots \\
\mathbf{c}_{S, 1} & \cdots & \mathbf{c}_{S, N}
\end{array}\right]\left[\begin{array}{c}
\mathbf{X}_{1}(t) \\
\vdots \\
\mathbf{X}_{N}(t)
\end{array}\right]+\left[\begin{array}{ccc}
\mathbf{d}_{1,1} & \cdots & \mathbf{d}_{1, M} \\
\vdots & \ddots & \vdots \\
\mathbf{d}_{S, 1} \cdots & \cdots & \mathbf{d}_{S, M}
\end{array}\right]\left[\begin{array}{c}
\mathbf{U}_{1}(t) \\
\vdots \\
\mathbf{U}_{M}(t)
\end{array}\right]}
\end{gathered}
$$

where

$$
\mathbf{X}_{r}(t)=\left[\begin{array}{c}
X_{r\langle-h\rangle}(t) \\
\vdots \\
X_{r\langle h\rangle}(t)
\end{array}\right] \text { for } r=1,2, \ldots N
$$

A similar expression to (6) describes each vector $\mathbf{U}_{r}(t)$ for $r=1,2, \ldots, M$.

Submatrices $\mathbf{a}_{p, q}$ and $\mathbf{b}_{l, v}$ in (5a) are square and timeinvariant with Toeplitz arrangement:

$$
\mathbf{a}_{p, q}=\left[\begin{array}{ccccccc}
A_{p, q\langle 0\rangle} & A_{p, q\langle-1\rangle} & \cdots & A_{p, q\langle-h\rangle} & 0 & \cdots & 0 \\
A_{p, q\langle 1\rangle} & A_{p, q\langle 0\rangle} & \ddots & \ddots & \ddots & \ddots & \vdots \\
\vdots & \vdots & \ddots & \ddots & \ddots & \ddots & 0 \\
A_{p, q\langle h\rangle} & \ddots & \ddots & A_{p, q\langle 0\rangle} & A_{p, q\langle-1\rangle} & \ddots & A_{p, q\langle-h\rangle} \\
0 & \ddots & \ddots & \ddots & A_{p, q\langle 0\rangle} & \ddots & A_{p, q\langle-h+1\rangle} \\
\vdots & \ddots & \ddots & \ddots & \ddots & \ddots & \vdots \\
0 & \cdots & 0 & A_{p, q\langle h\rangle} & A_{p, q\langle h-1\rangle} & \cdots & A_{p, q\langle 0\rangle}
\end{array}\right]
$$

for $p, q=1,2, \ldots, N$, and

$$
\mathbf{b}_{l, v}=\left[\begin{array}{ccccccc}
B_{l, v\langle 0\rangle} B_{l, v\langle-1\rangle} & \cdots & B_{l, v\langle-h\rangle} & 0 & \cdots & 0 \\
B_{l, v\langle 1\rangle} & B_{l, v\langle 0\rangle} & \ddots & \ddots & \ddots & \ddots & \vdots \\
\vdots & \vdots & \ddots & \ddots & \ddots & \ddots & 0 \\
B_{l, v\langle h\rangle} & \ddots & \ddots & B_{l, v\langle 0\rangle} & B_{l, v\langle-1\rangle} & \ddots & B_{l, v\langle-h\rangle} \\
0 & \ddots & \ddots & \ddots & B_{l, v\langle 0\rangle} & \ddots & B_{l, v\langle-h+1\rangle} \\
\vdots & \ddots & \ddots & \ddots & \ddots & \ddots & \vdots \\
0 & \cdots & 0 & B_{l, v\langle h\rangle} & B_{l, v\langle h-1\rangle} & B_{l, v\langle 0\rangle}
\end{array}\right]
$$

for $l=1,2, \ldots, N$ and $v=1,2, \ldots, M . A_{p, q\langle k\rangle}$ and $B_{l, v\langle k\rangle}$ are the complex Fourier coefficients of $a_{p, q}(t)$ and $b_{l, v}(t)$, respectively.

Submatrices in (5b) are also Toeplitz matrices whose elements are the complex Fourier series coefficients, for 
instance, $\mathbf{c}_{1,1}$ and $\mathbf{d}_{1,1}$ are square Toeplitz matrices composed by the complex Fourier series of $c_{1,1}(t)$ and $d_{1,1}(t)$, respectively. Finally, $\mathcal{D}$ is a diagonal matrix known as operation matrix of differentiation; its main diagonal is $\left[\begin{array}{lll}-j h \omega_{0} & \cdots & j h \omega_{0}\end{array}\right]$. Notice that system (5) gives the explicit solution of the time evolution of each complex Fourier series coefficient of each state variable without resorting to any numerical integration method. In addition to this, system (5) can be transformed into a harmonic transfer function. This modeling approach is especially useful for accurately analyzing the harmonic relationships among multiple harmonic sources, frequency-dependent components, transmission lines and dynamic loads by means of an LTI state-space model of increased order. Recent applications can be found in [91]-[94]. A salient feature of (5a) is the straightforward computation of the steady state as follows:

$$
\left[\begin{array}{c}
\mathbf{X}_{1}(t) \\
\vdots \\
\mathbf{X}_{N}(t)
\end{array}\right] \approx-\left[\begin{array}{ccc}
\mathbf{a}_{1,1}-\mathcal{D} \cdots & \mathbf{a}_{1, N} \\
\vdots & \ddots & \vdots \\
\mathbf{a}_{N, 1} & \cdots & \mathbf{a}_{N, N}-\mathcal{D}
\end{array}\right]^{-1}\left(\left[\begin{array}{ccc}
\mathbf{b}_{1,1} & \cdots & \mathbf{b}_{1, M} \\
\vdots & \ddots & \vdots \\
\mathbf{b}_{N, 1} & \cdots & \mathbf{b}_{N, M}
\end{array}\right]\left[\begin{array}{c}
\mathbf{U}_{1} \\
\vdots \\
\mathbf{U}_{M}
\end{array}\right]\right)
$$

It is worth mentioning that this modeling approach can be applied to nonlinear systems without previous linearization. For instance, references [90], [91], [95] present nonlinear EHD models. Obtaining such nonlinear models is not straightforward in general. Nevertheless, for stability analysis purposes based on eigenvalues it is possible to linearize the original nonlinear time-domain state-space model around a given periodic steadystate solution and then transform it to the EHD using the process described in this section. Linearization of a time-varying periodic nonlinear model implies to obtain a model where the input (the switching signal in case of closed-loop controlled power electronic-based power systems) is not present in the system matrix, rather than eliminate its time-varying (or periodic) characteristic. This is usually done by fixing the periodic switching signals in the system matrix around a desired periodic-operating orbit. This process can be automated into a professional computer program. Ref. [94] presents analytical and numerical approaches for the EHD modeling of nonlinear switched systems with $d q$ closed-loop controllers for power electronic-based power systems.

\section{Numerical Laplace transform (NLT)}

The systems of integro-differential equations that define typical power devices or networks for transient analysis become simple algebraic equations in the frequency domain. The straightforward solution of these expressions, usually in the form of voltages and/or currents, can then be converted into the time domain using a frequency-time transformation. From different options available, the numerical Laplace transform (NLT) is well-known for its accuracy, versatility and computational efficiency in the electromagnetic transient analysis of power components and systems [96]-[99]. The present paper demonstrates that the NLT can also be useful for electromagnetic transient stability studies, as shown in Section VI.C. A brief overview of this method is presented below.

Starting from the inverse Laplace transform of the real and causal function $\mathrm{F}(\mathrm{s})$ :

$$
f(t)=\frac{e^{c t}}{\pi} \operatorname{Re}\left\{\int_{0}^{\Omega} F(s) e^{j \omega t} d \omega\right\}
$$

In (10) $c$ and $\omega$ are the real and imaginary components of the complex frequency $s$. In addition, the integral operation has been truncated considering that $\Omega$ is the maximum angular frequency present in the analysis. This truncation produces Gibbs oscillations, which can be damped multiplying $F(s)$ by a window function, as described in [96], [97]. The numerical version of (10) for a maximum simulation time $T$ and including the window function $\sigma(\omega)$ is given by

$$
f_{n}=\frac{e^{c n \Delta t}}{\pi} \operatorname{Re}\left\{\sum_{k=0}^{1}\left[F_{\bar{k}} \sigma_{\bar{k}} e^{j \bar{k} \Delta \omega n \Delta t} 2 \Delta \omega\right]\right\}
$$

where

$$
\begin{gathered}
\bar{k}=2 k+1, \quad k=0,1, \ldots, N-1 \\
f_{n}=f(n \Delta t), \quad n=0,1, \ldots, N-1 \\
\Delta t=T / N \\
\Delta \omega=\pi / N \\
c=2 \Delta \omega
\end{gathered}
$$

In addition, $F_{\bar{k}}$ and $\sigma_{\bar{k}}$ are the discrete versions of $F(s)$ and $\sigma(\omega)$. Notice that (11) and (12) consider a discrete frequency sampling in $N$ steps of size $2 \Delta \omega$. This is known as the oddsampling definition of the inverse numerical Laplace transform, which has proven to offer enhanced performance when compared to the use of conventional sampling. The term $c$ (real part of $s$ ) as defined in (12e) is used as a damping factor to reduce the aliasing errors produced by the discretization of (10). Eq. (11) is conveniently expressed so that the term in brackets corresponds to the Inverse Fast Fourier Transform (ifft) algorithm, thus allowing a very efficient numerical computation.

Alternative approaches [100] and sampling schemes [101] for frequency-time transformation have been proposed in recent years and can be explored for transient stability applications.

\section{APPLICATION EXAMPLE: ELECTROMAGNETIC INTERACTION BETWEEN A VSC AND AN AC NETWORK}

\section{A. Test system description}

As an example, the interactions between a voltage source converter (VSC) and a passive network, sketched in Fig. 2, are analyzed. The aim is to analyze harmonic interactions and the impact of resonances on the converter control response. The network has to be represented by models which accurately capture the relevant dynamics and phenomena over the frequency range of interest.

Similarly, the converter equivalent impedance representation needs to accurately represent dynamics in the frequency range above the nominal frequency. Fig. 3 shows the control loops of interest. In this range of higher frequencies, the converter dynamics that have the largest influence are the current controller $G_{c c}$, the overall time delay $e^{-t_{d} s}$, the voltage feedforward filter $F_{f f}$, and the converter reactor dynamics $L s+R$. The network-side inverter is a sinusoidal pulse width modulated (PWM) three-phase, two-level, voltage source converter. The dynamic impact of the PWM is represented by a pure delay $e^{-t_{d} s}$. The parameters used for the study are given in Table I. 


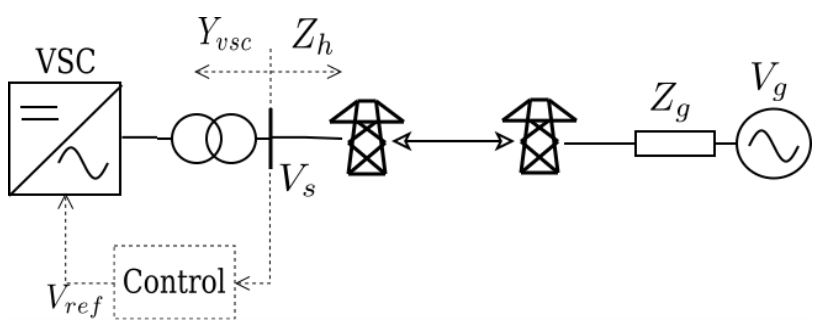

Fig. 2 Network composed of a voltage source converter and a transmission line terminated by a short-circuit impedance.

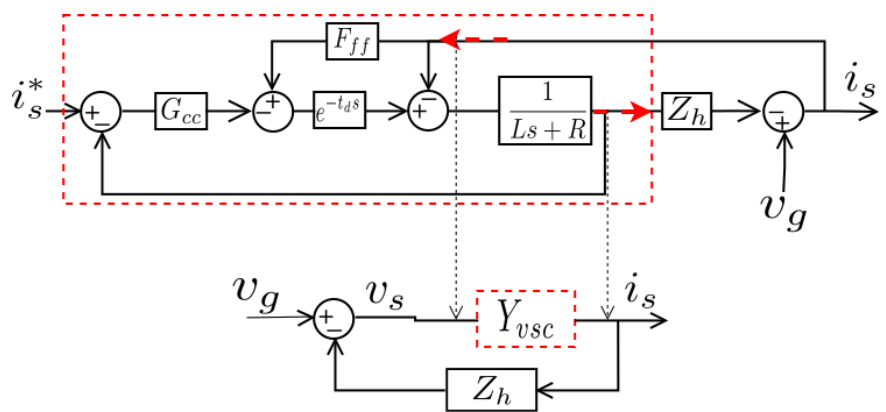

Fig. 3 Block diagram of the dynamic VSC model with the interconnection with the network represented by $Z_{h}$ and its relationship with the impedance-based stability approach.

TABLE I PARAMETERS OF THE VOLTAGE SOURCE CONVERTER

\begin{tabular}{lcc}
\hline \multicolumn{1}{c}{ Definition } & $\begin{array}{c}\text { Dynamic } \\
\text { Representation }\end{array}$ & Parameters \\
\hline Phase reactor & $L s+R$ & $L=0.12 m H R=0.3 \Omega$ \\
Current controller & $K p+K_{i} s /\left(s^{2}+\omega_{N}^{2}\right)$ & $K_{p}=116, K_{i}=5800$ \\
Feed-forward filter & $\alpha_{f f} /\left(s+\alpha_{f f}\right)$ & $\alpha_{f f}=2 \pi 350$ \\
Delay & $e^{-t_{d} s}$ & $t_{d}=200 \mu s$ \\
\hline \hline
\end{tabular}

The impedance-based analysis has been widely used and established for different representations of the instantaneous variables. However, since the aim of this paper is to compare different methods in the frequency domain and the necessary modeling of passive elements, only the most generic $a b c$ representation is considered. This is also justified from the perspective of black-box representation: $a b c$ quantities can be directly measured or calculated in EMT simulation tools and do not require the processing that $d q$ or sequence representations need. In addition, $a b c$ quantities are not influenced by internal dynamics used in the respective transformations. Nonetheless, all the presented modeling approaches can handle both phase and $d q$ models. In any case, a wideband modeling approach is required to avoid overlooking oscillation modes corresponding to frequencies above the traditional range, as shown in the next section. In a more general case, a power electronic-based system model can be a mix of phase and $d q$ variables; typically control systems are in $d q$ frame of reference, and network power components are in phase domain.

\section{B. Results from Input impedanceladmittance approach}

The lower part of Fig. 3 shows how the closed-loop system (converter and passive network) can be considered from the control stability study perspective. The network harmonic impedance $Z_{h}$ represents the frequency-dependent behavior of the network as seen at the PCC. Fig. 3 also shows the reduction of the converter dynamics by means of an equivalent admittance. Doing so, the interaction between the converter and network dynamics can be represented as a typical feedback system. Consequently, the stability of the system can be evaluated by typical criteria in control feedback systems such as the Nyquist criterium.

The equivalent admittance of the converter is derived from the block diagram shown in Fig. 3, representing converter control loops and dynamics as

$$
Y_{v s c}=\frac{1-e^{-t_{d} s} F_{f f}}{L s+R+e^{-t_{d} s} G_{c c}}
$$

The system sketched in Fig. 2 was built and simulated in PSCAD. The converter was modeled as a controllable voltage source through the phase reactor with the voltage input determined by the control.

The time-domain response of the phase voltage at the PCC is shown in Fig. 4. In this simulation the interaction between converter and transmission network is simulated at $t=1.5 \mathrm{~s}$. The waveform presents an amplifying high-frequency oscillation at $2550 \mathrm{~Hz}$ as indicated in the FFT applied to a window of this response (Fig. 4(c)).

The observed instability arises from the interconnection of the converter, originally stable, to the network. The interaction between both components results in a change in the overall frequency spectrum of the system. A resonance occurs when the magnitude plots of the connected impedances at a given node intersect each other. Its magnitude depends on the angle difference between both impedances at the frequency of the intersection.

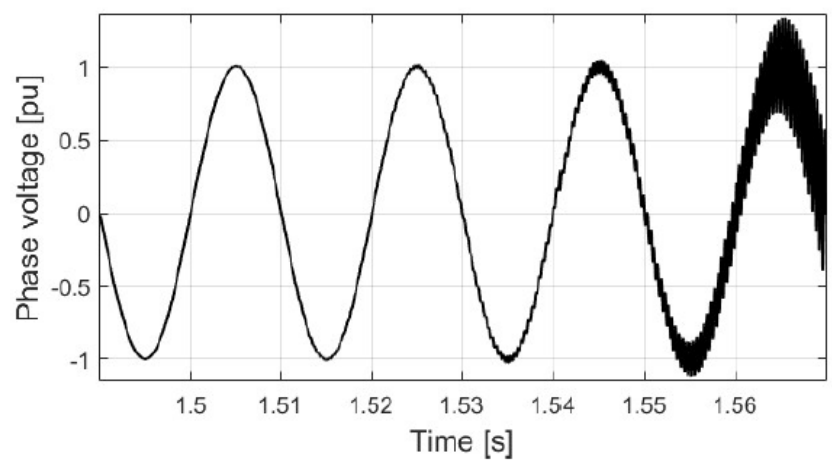

(a)

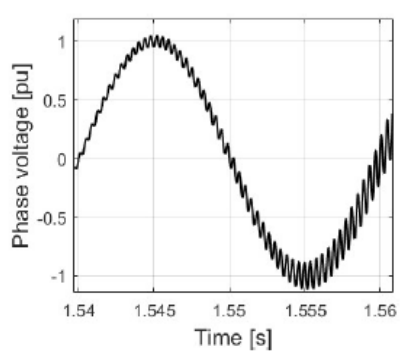

(b)

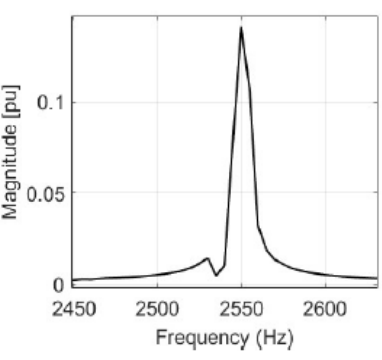

(c)
Fig. 4 (a) Time-domain response of the phase voltage at the PCC from the complete system simulated in an EMT software, (b) detailed window of the time-domain response, (c) FFT applied to the response in the window $t=$ $1.53-1.535 s$ 
Fig. 5 shows the Bode diagram of the network and the VSC equivalent impedance. The resulting resonances are indicated. The most interesting point occurs at $2520 \mathrm{~Hz}$, where both curves intersect and coincide with a non-passive region of the VSC equivalent impedance.

Typical line models fail at representing the system response at the range of frequencies of this case. Following common assumptions and approaches for transmission line representation, this line, with $\gamma l=0.098 \ll 1$, could be represented as a simple series impedance [11]. Expectedly, the use of such simplification has an impact on the estimated system response. Here, the line is also represented by typical simplifications such as the equivalent $\pi$ section or the constantparameter distributed model. These representations are usually built from the equivalent RLGC values at the fundamental frequency because this is the most likely provided or accessible data of the line. The corresponding series and shunt elements as calculated in (14) consider the effect of the distributed nature of the constant or frequency-dependent parameters.

$$
\begin{aligned}
& Z_{\text {series }}=Z l \sinh \gamma l / \gamma l \\
& Y_{\text {shunt }}=Y l \tanh \frac{\gamma l}{2} / \gamma l
\end{aligned}
$$

Fig. 6 shows the Bode plot of the equivalent impedance of the passive network as seen from the PCC by using both aforementioned line simplifications and comparing them with the more accurate frequency-dependent wideband representation. This figure demonstrates how such a representation, which has its origin in typical phasor-based representations, fails in assessing a correct frequency and damping of the system's natural frequencies. These inaccuracies result in an incorrect estimation of the harmonic instabilities during grid integration studies. The Bode plots of the three different transfer functions $Y_{v s c} Z_{h}$ are shown in Fig. 7 and the resulting oscillatory modes are detailed in Table II.

The instability of the system occurs at the vicinity of the second natural frequency of the transmission line. This is estimated with different levels of accuracy and effectiveness when using different line representations. The relative error with respect to the frequency of oscillations obtained in the time-domain solution, $2550 \mathrm{~Hz}$, is $26 \%$ for the conventional $\pi$ section, $12 \%$ for the Bergeron model, and $1.2 \%$ for the frequency-dependent representation. Significantly, the use of the Bergeron model results in multiple and infinite low-damped oscillatory modes and even instabilities, which do not correspond to the results obtained with the more accurate frequency-dependent line models.

\begin{tabular}{ccc}
\multicolumn{2}{c}{ TABLE II OSCILLATORY MODES FROM THE USE OF DIFFERENT LINE MODELS } \\
\hline PI equivalent & DCP model & FD model \\
\hline $1020 \mathrm{~Hz}\left(\mathrm{PM}=2^{\circ}\right)$ & $1040 \mathrm{~Hz}\left(\mathrm{PM}=17^{\circ}\right)$ & $1020 \mathrm{~Hz}\left(\mathrm{PM}=2^{\circ}\right)$ \\
$1890 \mathrm{~Hz}\left(\mathrm{PM}=-3^{\circ}\right)$ & $2240 \mathrm{~Hz}\left(\mathrm{PM}=-12^{\circ}\right)$ & $1890 \mathrm{~Hz}\left(\mathrm{PM}=-3^{\circ}\right)$ \\
& $3640 \mathrm{~Hz}\left(\mathrm{PM}=3^{\circ}\right)$ & \\
& $6670 \mathrm{~Hz}\left(\mathrm{PM}=-2^{\circ}\right)$ & \\
\hline \hline
\end{tabular}
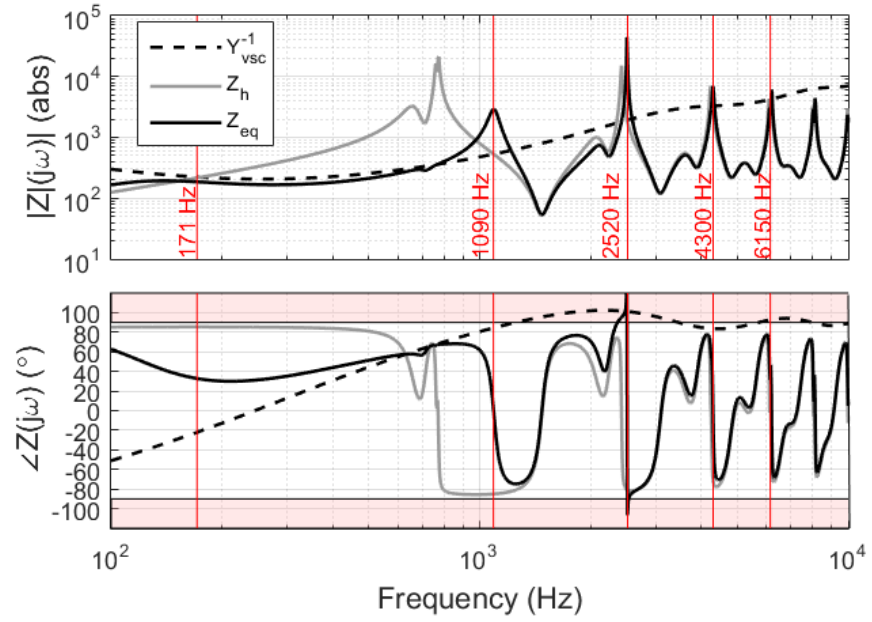

Fig. 5 Bode diagram of the VSC equivalent and network impedances. The nonpassive region is shown in shaded area.
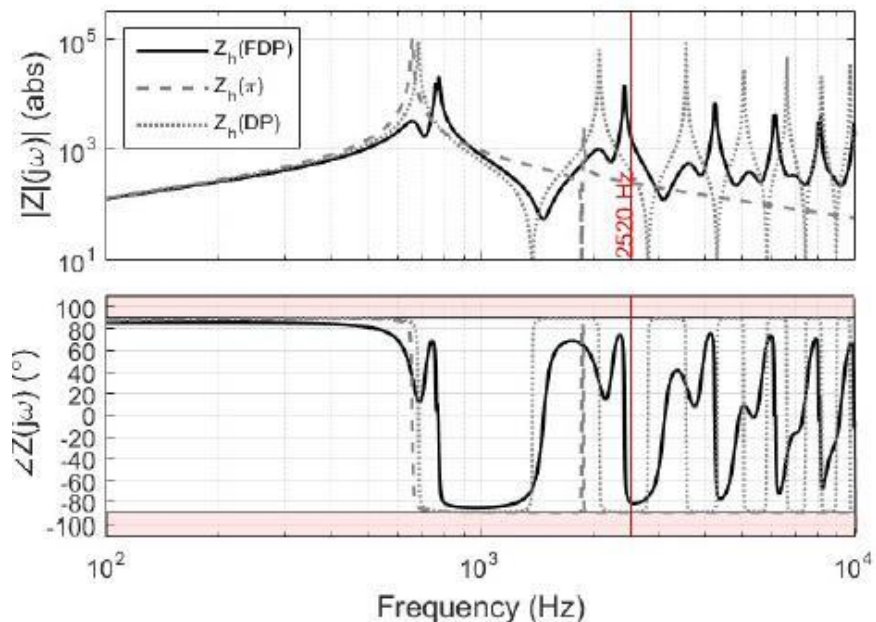

Fig. 6 Bode plot of the network impedance represented by frequency-dependent parameters (in solid), by a $\pi$ equivalent (in dashed grey) and by a constant distributed-parameter model (in dotted grey).

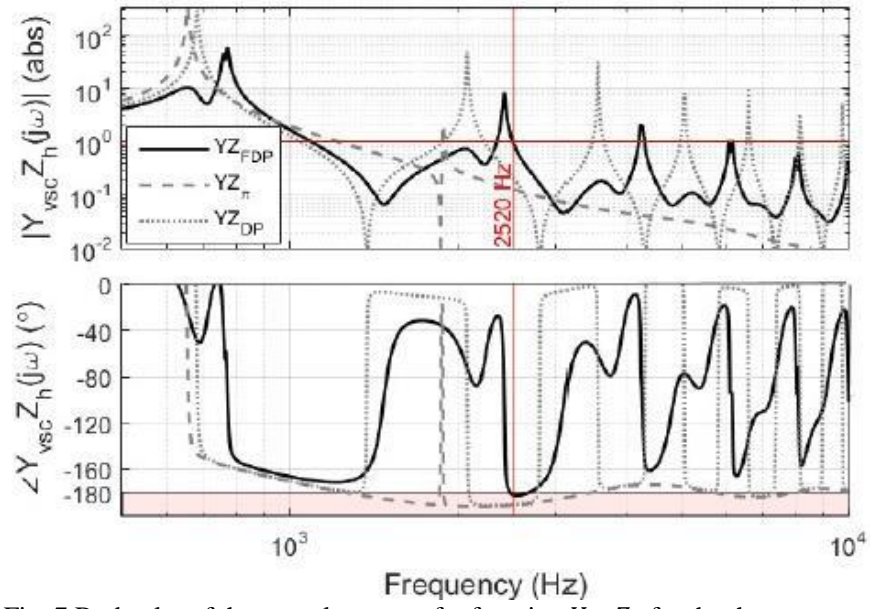

Fig. 7 Bode plot of the open-loop transfer function $Y_{v s c} Z_{h}$ for the three types of transmission line representation. 


\section{Results using the EHD}

The test system is described in the EHD through the model defined by (5a). The VSC is modeled using the fundamental frequency model. The time domain solution of phase A voltage at the PCC, which was reconstructed using the EHD solution, is shown in Fig. 8 and compared against the solution obtained with PSCAD. Although the oscillation modes can be approximated using the Fast Fourier Transform (FFT), this subsection alternatively presents the eigenvalues of the system matrix of (5a).

Fig. 9 shows the poles around the imaginary axis of the complex plane. Notice that the oscillation modes identified in the Bode diagram of Fig. 5 are clearly distinguished, but there are also more oscillation modes. The only unstable oscillation modes for this case are around $2.5 \mathrm{kHz}$, i.e. $85.583 \pm 15746 i$, $85.583 \pm 16060 i, \quad 85.583 \pm 16375 i, \quad 73.246 \pm 16281 i$, $73.246 \pm 15967 i$, and $73.246 e \pm 15653 i$, all in $\mathrm{rad} / \mathrm{s}$. The oscillation frequencies corresponding to these modes are 2506.1, 2556, 2606.2, 2591.2, 2541.2, and 2491.3, all in Hz. These oscillation modes are very close to the value of $2520 \mathrm{~Hz}$ shown in the Bode diagram of Fig. 5. The slight differences among these modes, both in the real and imaginary parts, are attributed to the unbalanced nature of the transmission line, since it is not assumed transposed. Fig. 9 also shows oscillation modes around all the remaining resonance frequencies shown in Fig. 5.

In this EHD case study, the network towards the right of the VSC terminals was represented using a frequency-dependent network equivalent. This equivalent was identified using vector fitting with 35 poles [102]-[104].

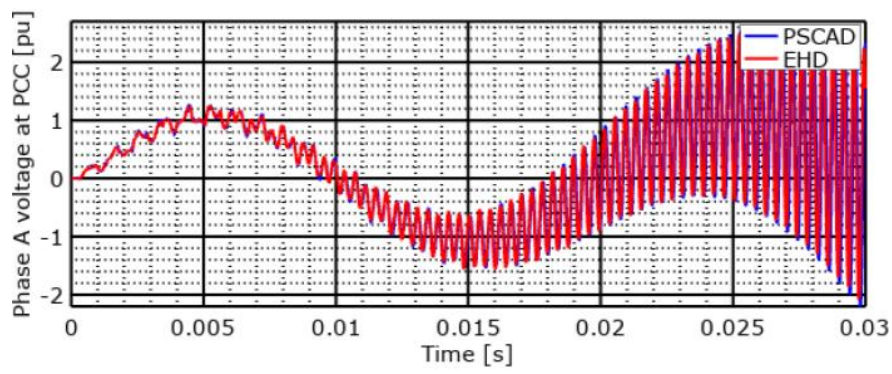

Fig. 8 Solution comparison between PSCAD and EHD of the zero-state response of the phase A voltage at the PCC (unstable case).

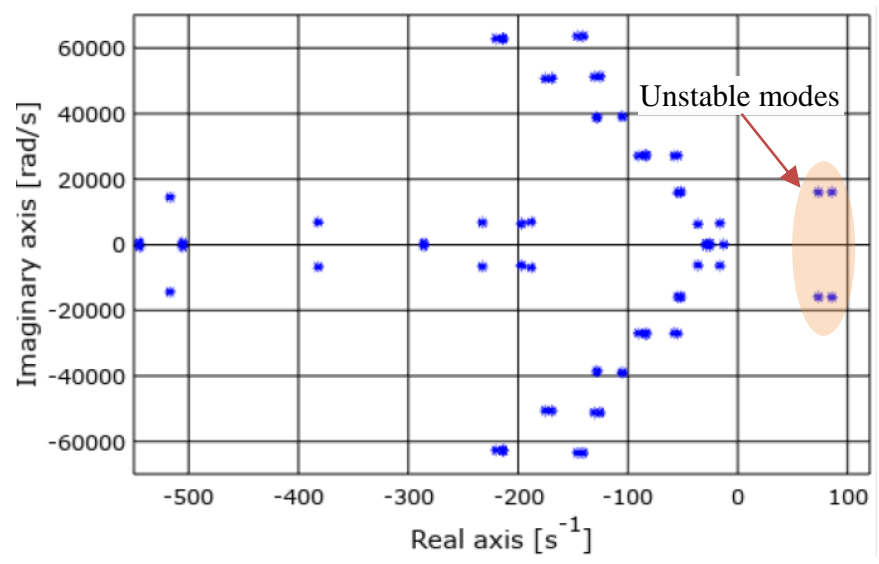

Fig. 9 Pole mapping of the EHD model for the (unstable case).
D. Results from NLT approach with admittance matrix model of the system

The network illustrated in Fig. 3 can also be described by means of the following admittance matrix model in the frequency domain:

$$
\begin{gathered}
{\left[\begin{array}{cc}
Y_{\text {vsc }}+Y_{\text {shunt }}+Z_{\text {series }}^{-1} & -Z_{\text {series }}^{-1} \\
-Z_{\text {series }}^{-1} & Y_{\text {shunt }}+Z_{\text {series }}^{-1}+Z_{s c}^{-1}
\end{array}\right]\left[\begin{array}{c}
V_{L} \\
V_{R}
\end{array}\right]} \\
=\left[\begin{array}{c}
Z_{\text {sc }}^{-1} V_{\text {source }} \\
0
\end{array}\right]
\end{gathered}
$$

where $V_{L}$ and $V_{R}$ are the nodal voltages measured at the left and right terminals of the transmission line, while $V_{\text {source }}$ represents the voltage source from the Thevenin equivalent connected at the right terminal of the line, as shown in Fig. 2. The 3-phase transmission line is modeled as fully frequency-dependent. Eq. (15) is solved for the nodal voltages vector and the resulting voltages are transformed to time domain responses using the inverse NLT, as described in Section V-C. In this case, it is assumed that the converter-network interaction starts at $t=0$.

Fig. 10 shows the time-domain response at all 3 phases of the PCC. In complete agreement with the results from the use of the other methods, it is shown that the system under study presents an evident instability due to the interaction between the transmission line and the VSC. This figure also shows that this instability disappears when the transmission line is removed from the simulation. Moreover, Fig. 11 shows the FFT applied to the unstable response at the PCC. The oscillatory modes are very similar to those previously listed in Table II, in particular, those corresponding to the inclusion of the frequencydependent line model.

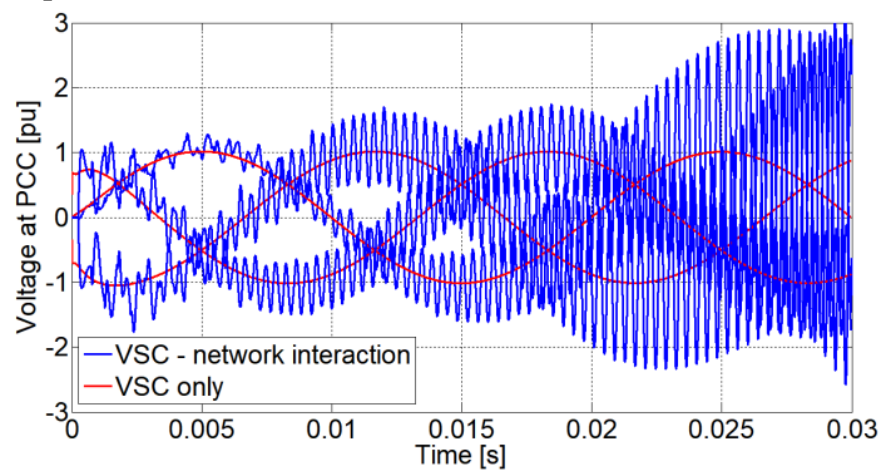

Fig. 10 Transient voltage response at the PCC obtained via the inverse NLT.

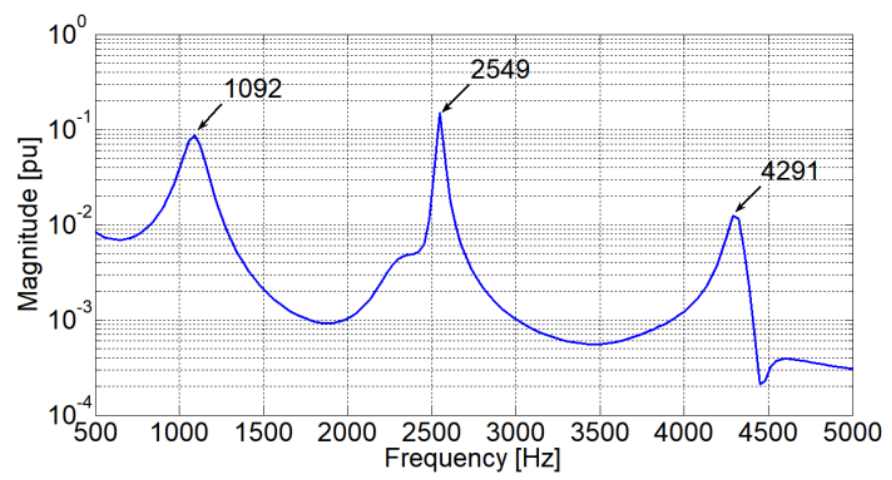

Fig. 11 FFT applied to phase A of the transient voltage response at the PCC. 


\section{E. Comparison assessment}

The input impedance/admittance stability analysis approach is based on the Nyquist stability criterium using the minor loop defined by the grid and internal impedances. This method does not require the computation of time-domain waveforms or eigenvalues and allows the use of frequency-dependent and distributed parameter models without resorting to approximations. It also reveals the unstable oscillation frequencies using simple Bode plots. However, since this approach is based on impedance/admittance matrices in the frequency domain that represent the systems on both sides of the PCC, it is necessary to have linearized versions of the real systems.

On the other hand, the EHD is based on a state-space formulation, and the stability can be evaluated without the use of numerical integration. It is only necessary to calculate the eigenvalues of the state matrix. This process can be timeconsuming for large-scale systems, especially if the harmonic distortion and cross-coupling need to be considered. For these cases, some approaches for getting reduced models have been proposed [92], [93], [95], [105]-[107]. It is also possible to obtain the transfer function from the EHD model to perform stability analysis.

Finally, the NLT-based modeling approach described in Sections V.C and VI.D resorts to the admittance matrix model of the complete system. This formulation also permits the use of frequency-dependent distributed-parameter models without approximations. Unlike the input impedance/admittance stability analysis approach, the NLT utilizes the time-domain waveforms to determine if the system is stable or not. This feature can be a drawback in case of having unstable eigenvalues close to the imaginary axis because it could mean long simulation times. In addition, the NLT can present numerical errors related to the discretization and truncation of the frequency spectrum. However, efficient and robust strategies have been proposed to avoid these issues as well as to include nonlinearities [96], [97], [107]. Although there is no previous experience with converter control design for transient stability analysis using this tool, it is expected to be useful to test and evaluate controllers throughout the design process.

Table III summarizes and compares the capabilities and limitations of each modeling approach described in this paper. Similar criteria to those presented in this table are also discussed in [2], [108], [109].

A different number of ticks is used in Table III to further qualify each method's ability to handle specific criteria under comparison. Two ticks mean that the method is fully capable of handling a condition, and one tick means that the method is partially capable. Also in Table III, switching harmonics refer to the harmonics generated by the commutation process of power electronic converters, while harmonic cross-coupling refers to the interaction between different harmonics, i.e., a specific harmonic depends not only on itself but also on the others. In the case of power-electronic-based systems, this coupling also affects the switching harmonics generated. EHD expresses the harmonic cross-coupling through the Toeplitz matrices (7)-(8). NLT and impedance/admittance methods can handle this coupling explicitly in the admittance/impedance matrix model.

The impedance/admittance approach and the NLT can easily preserve confidential system information by means of transfer function representation and the use of network equivalents. In contrast, the EHD relies on a state-space representation that requires detailed system information. However, in the linear fashion the EHD method can also be rewritten in terms of transfer functions, thus enabling protection of confidential information.

TABLE III PERFORMANCE COMPARISON OF ELECTROMAGNETIC TRANSIENT STABILITY ANALYSIS METHODS

\begin{tabular}{|c|c|c|c|}
\hline Criteria & Impedance/ admittance & NLT & EHD \\
\hline Modularity & $\checkmark \checkmark$ & $\checkmark \checkmark$ & $\checkmark$ \\
\hline Wideband models & $\checkmark \checkmark$ & $\checkmark \checkmark$ & $\checkmark$ \\
\hline Protects confidential information & $\checkmark \checkmark$ & $\checkmark \checkmark$ & $\checkmark$ \\
\hline Time-varying behavior & Averaging & $\checkmark$ & $\checkmark$ \\
\hline Nonlinear-periodic systems & $x$ & $\checkmark$ & $\checkmark$ \\
\hline Frequency-dependent parameters & $\checkmark$ & $\checkmark \checkmark$ & $\checkmark$ \\
\hline Distributed parameters & $\checkmark$ & $\checkmark \checkmark$ & $\checkmark$ \\
\hline Switching harmonics & $x$ & $\checkmark$ & $\checkmark \checkmark$ \\
\hline Harmonic cross-coupling & $\checkmark$ & $\checkmark \checkmark$ & $\checkmark \checkmark$ \\
\hline Easy modeling & The easiest & Moderate & Computer assisted \\
\hline Easy analysis & The easiest & Moderate & Computer assisted \\
\hline Serves as a control design tool & $\checkmark \checkmark$ & $\checkmark$ & $\checkmark$ \\
\hline Suitable for large scale systems & $\checkmark \checkmark$ & $\checkmark$ & $\checkmark$ \\
\hline Stability analysis & Transfer function (TF) & $\begin{array}{l}\text { Time domain solution } \\
\text { (TDS) }\end{array}$ & $\begin{array}{c}\text { Eigenvalues, TDS, } \\
\text { selective modal analysis } \\
\text { and TF }\end{array}$ \\
\hline Applications & $\begin{array}{c}\text { Stability analysis, control } \\
\text { design }\end{array}$ & $\begin{array}{c}\text { Stability analysis, control } \\
\text { design. }\end{array}$ & $\begin{array}{c}\text { Stability analysis, control } \\
\text { design, harmonic } \\
\text { analysis }\end{array}$ \\
\hline
\end{tabular}




\section{CONCLUSIONS}

This paper presents a comprehensive state-of-the-art review and discussion of the application of three frequency domain methods to analyze the influence of the modeling approaches used in the representation of power systems for electromagnetic transient stability studies, i.e., studies including frequencies above the range of traditional transient stability and related to the widespread penetration of power electronic devices.

The analysis of harmonic interactions in the frequency domain for this sort of studies has multiple advantages and thereby complement other methodologies: First, besides indicating instabilities, the analysis allows to address the relative stability to estimate how close the system is to being unstable or to have sustained oscillations. Second, it makes it possible to understand the root cause of the problem and apply the necessary countermeasures to mitigate it either in the form of the installation of a new passive component or by designing a new control loop to add the necessary phase margin. Third, it can essentially be used as a 'black-box approach': the internal information of converter dynamics is not necessary. Besides, the interconnection and the interaction with control dynamics results in new network resonances; therefore, this information is necessary for other studies where the knowledge of the resonances is of great importance, such as harmonic analysis or filter design.

Finally, the NLT is introduced as a new tool for electromagnetic transient stability. The results obtained with this tool are in high agreement with the EHD and the impedance/admittance methods.

\section{ACKNOWLEDGMENTS}

The authors would like to thank professors Jesús Rico (Universidad Michoacana de San Nicolás de Hidalgo) and Jian Sun (Rensselaer Polytechnic Institute) for their invaluable feedback, suggestions, and comments. Juan Segundo would like to thank the project C0014-2016-01 (275495) Institutional Links CONACYT -British Council for the financial support and facilities granted for this investigation. The work of $\mathrm{J}$. Beerten was supported by the Research Foundation-Flanders.

\section{REFERENCES}

[1] A. Greenwood, Electrical Transients in Power Systems, 2nd ed. John Wiley \& Sons, 1991.

[2] J. Sun et al., "Renewable energy transmission by HVDC across the continent: system challenges and opportunities," CSEE J. Power Energy Syst., vol. 3, no. 4, pp. 353-364, Dec. 2017.

[3] T. Yalcin, M. Özdemir, P. Kostyla, and Z. Leonowicz, "Analysis of supra-harmonics in smart grids," presented at the Proc. 2017 IEEE International Conference on Environment and Electrical Engineering and 2017 IEEE Industrial and Commercial Power Systems Europe (EEEIC / I CPS Europe), 2017, pp. 1-4.

[4] C. Buchhagen, C. Rauscher, A. Menze, and J. Jung, "BorWin1 - First Experiences with harmonic interactions in converter dominated grids," in Proc. International ETG Congress 2015; Die Energiewende - Blueprints for the new energy age, 2015, pp. 1-7.

[5] H. Saad, "Performance analysis of INELFE link with control replicas," presented at the Workshop on Real-time Simulation to support installation and operation of HVDC/FACTS on transmission grids, CIGRE Session 46, Paris, France, 2016.

[6] C. Rathke and M. Greeve, "Operating Experience of HVDC Links Behaviour After Switching Events in the Onshore Grid," presented at the Proceedings in CIGRE B4 Colloquium, Manitoba, Canada, 2017.
[7] H. Rao and S. Xu, "Operational Experiences of Luxi BTB and Nao'ao MTDC projects in China," presented at the Proceeding in CIGRE B4 Colloquium, Manitoba, Canada, 2017.

[8] M. Menth, S. M., "Low-frequency power oscillations in electric railway systems," Elektr. Bahnen, vol. 104, no. 2, pp. 216-221, 2006.

[9] E. Mollerstedt and B. Bernhardsson, "Out of control because of harmonics-an analysis of the harmonic response of an inverter locomotive," IEEE Control Syst., vol. 20, no. 4, pp. 70-81, Aug. 2000.

[10] J. H. R. Enslin and P. J. M. Heskes, "Harmonic interaction between a large number of distributed power inverters and the distribution network," IEEE Trans. Power Electron., vol. 19, no. 6, pp. 1586-1593, Nov. 2004.

[11] P. Kundur, Power System Stability and Control. New York: McGraw-Hill Professional, 1994.

[12] P. Kundur et al., "Definition and classification of power system stability IEEE/CIGRE joint task force on stability terms and definitions," IEEE Trans. Power Syst., vol. 19, no. 3, pp. 1387-1401, 2004.

[13] P. W. Sauer, M. A. Pai, and J. H. Chow, Power System Dynamics and Stability: With Synchrophasor Measurement and Power System Toolbox. NJ: Wiley-IEEE Press, 2017.

[14] T. van Cutsem and C. Vournas, Voltage Stability of Electric Power Systems. New York: Springer Verlag, 2007.

[15] J. Arrillaga and N. R. Watson, Power System Harmonics. John Wiley \& Sons, 2004.

[16] I. A. Hiskens and M. A. Pai, "Trajectory sensitivity analysis of hybrid systems," IEEE Trans. Circuits Syst. Fundam. Theory Appl., vol. 47, no. 2, pp. 204-220, Feb. 2000.

[17] M. D. O. Faruque et al., "Real-Time Simulation Technologies for Power Systems Design, Testing, and Analysis," IEEE Power Energy Technol. Syst. J., vol. 2, no. 2, pp. 63-73, Jun. 2015.

[18] X. Wang, F. Blaabjerg, and W. Wu, "Modeling and Analysis of Harmonic Stability in an AC Power-Electronics-Based Power System," IEEE Trans. Power Electron., vol. 29, no. 12, pp. 6421-6432, Dec. 2014.

[19] J. D. Ainsworth, "Harmonic instability between controlled static convertors and a.c. networks," Proc. Inst. Electr. Eng., vol. 114, no. 7, pp. 949-957, Jul. 1967.

[20] N. Fukuyama, Y. Sagisaka, K. Neri, and Y. Sekine, "Harmonic stability analysis of HVDC system directly connected to generators," Electr. Eng. Jpn., vol. 107, no. 5, pp. 18-26, Jan. 1987.

[21] X. Wang and F. Blaabjerg, "Harmonic Stability in Power Electronic Based Power Systems: Concept, Modeling, and Analysis," IEEE Trans. Smart Grid, pp. 1-1, 2018.

[22] J. Kwon, X. Wang, F. Blaabjerg, C. L. Bak, V. S. Sularea, and C. Busca, "Harmonic Interaction Analysis in a Grid-Connected Converter Using Harmonic State-Space (HSS) Modeling," IEEE Trans. Power Electron., vol. 32, no. 9, pp. 6823-6835, Sep. 2017.

[23] A. Bayo-Salas, "Control interactions in power systems with multiple VSC HVDC converters," Doctoral dissertation, University of Leuven, Belgium, 2018.

[24] V. E. Wagner et al., "Effects of harmonics on equipment," IEEE Trans. Power Deliv., vol. 8, no. 2, pp. 672-680, Apr. 1993.

[25] B. S. Ram, J. A. C. Forrest, and G. W. Swift, "Effects of harmonics on converter transformer load losses," IEEE Trans. Power Deliv., vol. 3, no. 3, pp. 1059-1066, Jul. 1988.

[26] T. H. Ortmeyer, K. R. Chakravarthi, and A. A. Mahmoud, "The Effects of Power System Harmonics on Power System Equipment and Loads," IEEE Power Eng. Rev., vol. PER-5, no. 9, pp. 54-54, Sep. 1985.

[27] S. J. Lee, J. M. Kim, D. K. An, and J. P. Hong, "Equivalent Circuit Considering the Harmonics of Core Loss in the Squirrel-Cage Induction Motor for Electrical Power Steering Application," IEEE Trans. Magn., vol. 50, no. 11, pp. 1-4, Nov. 2014.

[28] F. Iov, F. Blaabjerg, and K. Ries, "Prediction of harmonic power losses in fuses located in DC-link circuit of an inverter," IEEE Trans. Ind. Appl., vol. 39, no. 1, pp. 2-9, Jan. 2003.

[29] M. A. S. Masoum and E. F. Fuchs, "Transformer magnetizing current and iron-core losses in harmonic power flow," IEEE Trans. Power Deliv., vol. 9, no. 1, pp. 10-20, Jan. 1994.

[30] L. H. S. Duarte and M. F. Alves, "The degradation of power capacitors under the influence of harmonics," presented at the Proc. 10th International Conference on Harmonics and Quality of Power, 2002, vol. 1, pp. 334-339.

[31] A. C. Delaiba, J. C. De Oliveira, L. A. Vilaca, and J. R. Cardoso, "The effect of harmonics on power transformers loss of life," presented at the Proc. 38th Midwest Symposium on Circuits and Systems, 1995, vol. 2, pp. 933-936.

[32] F. De La Rosa, Harmonics, Power Systems, and Smart Grids, Second Edition, 2nd ed. New York: CRC Press, 2015.

[33] T. A. Sakharuk, A. M. Stankovic, G. Tadmor, and G. Eirea, "Modeling of PWM inverter-supplied AC drives at low switching frequencies," 
IEEE Trans. Circuits Syst. Fundam. Theory Appl., vol. 49, no. 5, pp. 621631, May 2002.

[34] Y. Xu, Y. Chen, C. C. Liu, and H. Gao, "Piecewise Average-Value Model of PWM Converters With Applications to Large-Signal Transient Simulations," IEEE Trans. Power Electron., vol. 31, no. 2, pp. 13041321, Feb. 2016

[35] A. Beddard, C. E. Sheridan, M. Barnes, and T. C. Green, "Improved Accuracy Average Value Models of Modular Multilevel Converters," IEEE Trans. Power Deliv., vol. 31, no. 5, pp. 2260-2269, Oct. 2016.

[36] F. H. Guan, M. Zhao, X. Zhang, B. T. Shan, and Z. Liu, "Research on distributed generation technologies and its impacts on power system," presented at the Proc. 2009 International Conference on Sustainable Power Generation and Supply, 2009, pp. 1-6.

[37] A. Keane et al., "State-of-the-Art Techniques and Challenges Ahead for Distributed Generation Planning and Optimization," IEEE Trans. Power Syst., vol. 28, no. 2, pp. 1493-1502, May 2013.

[38] I. N. Santos, V. Ćuk, P. M. Almeida, M. H. J. Bollen, and P. F. Ribeiro, "Considerations on hosting capacity for harmonic distortions on transmission and distribution systems," Electr. Power Syst. Res., vol. 119, pp. 199-206, Feb. 2015.

[39] A. Luo, Q. Xu, F. Ma, and Y. Chen, "Overview of power quality analysis and control technology for the smart grid," J. Mod. Power Syst. Clean Energy, vol. 4, no. 1, pp. 1-9, Jan. 2016.

[40] J. Segundo-Ramírez, A. Medina, A. Ghosh, and G. Ledwich, "Stability boundary analysis of the dynamic voltage restorer in weak systems with dynamic loads," Int. J. Circuit Theory Appl., vol. 40, no. 6, pp. 551-569, 2012.

[41] X. Wang, F. Blaabjerg, and W. Wu, "Modeling and Analysis of Harmonic Stability in an AC Power-Electronics-Based Power System," IEEE Trans. Power Electron., vol. 29, no. 12, pp. 6421-6432, Dec. 2014.

[42] Z. Chen, A. Luo, H. Kuang, L. Zhou, Y. Chen, and Y. Huang, "Harmonic resonance characteristics of large-scale distributed power plant in wideband frequency domain," Electr. Power Syst. Res., vol. 143, pp. 5365, Feb. 2017.

[43] G. Agundis-Tinajero et al., "Harmonic Issues Assessment on PWM VSCBased Controlled Microgrids Using Newton Methods," IEEE Trans. Smart Grid, vol. 9, no. 2, pp. 1002-1011, Mar. 2018.

[44] J. Rocabert, A. Luna, F. Blaabjerg, and P. Rodríguez, "Control of Power Converters in AC Microgrids," IEEE Trans. Power Electron., vol. 27, no. 11, pp. 4734-4749, Nov. 2012.

[45] C. Wan, M. Huang, C. K. Tse, and X. Ruan, "Effects of Interaction of Power Converters Coupled via Power Grid: A Design-Oriented Study," IEEE Trans. Power Electron., vol. 30, no. 7, pp. 3589-3600, Jul. 2015.

[46] L. Harnefors, A. G. Yepes, A. Vidal, and J. Doval-Gandoy, "PassivityBased Controller Design of Grid-Connected VSCs for Prevention of Electrical Resonance Instability," IEEE Trans. Ind. Electron., vol. 62, no. 2, pp. 702-710, Feb. 2015.

[47] D. G. Infield, P. Onions, A. D. Simmons, and G. A. Smith, "Power Quality From Multiple Grid-Connected Single-Phase Inverters," IEEE Trans. Power Deliv., vol. 19, no. 4, pp. 1983-1989, Oct. 2004.

[48] F. Wang, J. L. Duarte, and M. A. M. Hendrix, "Grid-Interfacing Converter Systems With Enhanced Voltage Quality for Microgrid Application-Concept and Implementation," IEEE Trans. Power Electron., vol. 26, no. 12, pp. 3501-3513, 2011.

[49] I. C. Dias, M. Resener, L. N. Canha, and P. R. S. Pereira, "Transient stability study of an unbalanced distribution system with distributed generation," in Proc. 2014 IEEE PES Transmission Distribution Conference and Exposition - Latin America (PES T D-LA), 2014, pp. 15.

[50] V. Kaura and V. Blasko, "Operation of a phase locked loop system under distorted utility conditions," IEEE Trans. Ind. Appl., vol. 33, no. 1, pp. 58-63, Jan. 1997.

[51] D. Dong, B. Wen, D. Boroyevich, P. Mattavelli, and Y. Xue, "Analysis of Phase-Locked Loop Low-Frequency Stability in Three-Phase GridConnected Power Converters Considering Impedance Interactions," IEEE Trans. Ind. Electron., vol. 62, no. 1, pp. 310-321, Jan. 2015.

[52] A. Luo et al., "Large-scale photovoltaic plant harmonic transmission model and analysis on resonance characteristics," IET Power Electron., vol. 8, no. 4, pp. 565-573, 2015.

[53] L. H. Kocewiak, J. Hjerrild, and C. L. Bak, "Wind turbine converter control interaction with complex wind farm systems," IET Renew. Power Gener., vol. 7, no. 4, pp. 380-389, Jul. 2013.

[54] M. Amin and M. Molinas, "Understanding the Origin of Oscillatory Phenomena Observed Between Wind Farms and HVdc Systems," IEEE J. Emerg. Sel. Top. Power Electron., vol. 5, no. 1, pp. 378-392, Mar. 2017.

[55] J. Lv, P. Dong, G. Shi, X. Cai, H. Rao, and J. Chen, "Subsynchronous oscillation of large DFIG-based wind farms integration through MMC- based HVDC," in Proc. 2014 International Conference on Power System Technology, 2014, pp. 2401-2408.

[56] H. Liu and J. Sun, "Voltage Stability and Control of Offshore Wind Farms With AC Collection and HVDC Transmission," IEEE J. Emerg. Sel. Top. Power Electron., vol. 2, no. 4, pp. 1181-1189, Dec. 2014.

[57] J. Segundo-Ramirez and A. Medina, "Modeling of FACTS Devices Based on SPWM VSCs," IEEE Trans. Power Deliv., vol. 24, no. 4, pp. $1815-1823$, Oct. 2009.

[58] S. Zou, C. Li, Z. Du, Y. Zhao, and L. Zhao, "Analytical method for computing electromagnetic transient models of FACTS in hybrid simulation," in Proc. 2016 IEEE PES Asia-Pacific Power and Energy Engineering Conference (APPEEC), 2016, pp. 1316-1321.

[59] M. Basiri-Kejani and E. Gholipour, "Holomorphic Embedding LoadFlow Modeling of Thyristor-Based FACTS Controllers," IEEE Trans. Power Syst., vol. 32, no. 6, pp. 4871-4879, Nov. 2017

[60] J. Sun, "Impedance-Based Stability Criterion for Grid-Connected Inverters," IEEE Trans. Power Electron., vol. 26, no. 11, pp. 3075-3078, Nov. 2011.

[61] M. Cespedes and J. Sun, "Impedance Modeling and Analysis of GridConnected Voltage-Source Converters," IEEE Trans. Power Electron., vol. 29, no. 3, pp. 1254-1261, Mar. 2014.

[62] J. B. Glasdam, Harmonics in Offshore Wind Power Plants: Application of Power Electronic Devices in Transmission Systems. Springer, 2015.

[63] J. Lyu, X. Cai, and M. Molinas, "Frequency Domain Stability Analysis of MMC-Based HVdc for Wind Farm Integration," IEEE J. Emerg. Sel. Top. Power Electron., vol. 4, no. 1, pp. 141-151, Mar. 2016.

[64] L. Xu and L. Fan, "Impedance-Based Resonance Analysis in a VSCHVDC System," IEEE Trans. Power Deliv., vol. 28, no. 4, pp. 22092216, Oct. 2013.

[65] H. Saad, Y. Fillion, S. Deschanvres, Y. Vernay, and S. Dennetière, "On Resonances and Harmonics in HVDC-MMC Station Connected to AC Grid," IEEE Trans. Power Deliv., vol. 32, no. 3, pp. 1565-1573, Jun. 2017.

[66] A. Bayo-Salas, J. Beerten, J. Rimez, and D. V. Hertem, "Analysis of control interactions in multi-infeed VSC HVDC connections," Transm. Distrib. IET Gener., vol. 10, no. 6, pp. 1336-1344, 2016.

[67] G. Pinares, "Analysis of the DC dynamics of VSC-HVDC systems connected to weak AC grids using a frequency domain approach," in 2014 Power Systems Computation Conference, 2014, pp. 1-7.

[68] Y. Song and C. Breitholtz, "Nyquist Stability Analysis of an AC-Grid Connected VSC-HVDC System Using a Distributed Parameter DC Cable Model," IEEE Trans. Power Deliv., vol. 31, no. 2, pp. 898-907, Apr. 2016.

[69] G. Stamatiou and M. Bongiorno, "Stability Analysis of Two-Terminal VSC-HVDC Systems Using the Net-Damping Criterion," IEEE Trans. Power Deliv., vol. 31, no. 4, pp. 1748-1756, Aug. 2016.

[70] J. Beerten, S. D'Arco, and J. A. Suul, "Frequency-dependent cable modelling for small-signal stability analysis of VSC-HVDC systems," Transm. Distrib. IET Gener., vol. 10, no. 6, pp. 1370-1381, 2016.

[71] P. Panciatici, W. P. Leader, C. Pache, R. J. Maeght, and R. A. Weber, "eHIGHWAY 2050 Modular Development Plan of the Pan-European Transmission System 2050," Tech. Rep, 2016.

[72] "Best Paths - Demonstration." [Online]. Available: http://bestpathsproject.eu/en/demonstration/demo-2. [Accessed: 23-May-2017].

[73] R. D. Middlebrook, "Input filter considerations in design and applications of switching regulators," in Proc. IEEE Industrial Applications Soc. Annual Meeting, 1976, pp. 91-107.

[74] R. D. Middlebrook, "Design techniques for preventing input filter oscillations in switched- mode regulators," in Proc. Power Converter Conference, 1978, p. A3.1-A3.16.

[75] S. D. Sudhoff and S. F. Glover, "Modeling Techniques, Stability Analysis, and Design Criteria for DC Power Systems with Experimental Verification," in SAE Technical Paper, 1998.

[76] S. D. Sudhoff and S. F. Glover, "Three-dimensional stability analysis of DC power electronics based systems," in Proc. 2000 IEEE 31st Annual Power Electronics Specialists Conference, 2000, vol. 1, pp. 101-106.

[77] S. D. Sudhoff, S. F. Glover, P. T. Lamm, D. H. Schmucker, and D. E. Delisle, "Admittance space stability analysis of power electronic systems," IEEE Trans. Aerosp. Electron. Syst., vol. 36, no. 3, pp. 965973, Jul. 2000.

[78] X. Feng, J. Liu, and F. C. Lee, "Impedance specifications for stable DC distributed power systems," IEEE Trans. Power Electron., vol. 17, no. 2, pp. 157-162, Mar. 2002

[79] A. Riccobono and E. Santi, "A novel Passivity-Based Stability Criterion (PBSC) for switching converter DC distribution systems," in Proc. 2012 Twenty-Seventh Annual IEEE Applied Power Electronics Conference and Exposition (APEC), 2012, pp. 2560-2567.

[80] A. Bayo-Salas, J. Beerten, J. Rimez, and D. Van Hertem, "Impedancebased stability assessment of parallel VSC HVDC grid connections," in 
Proc. 11th IET International Conference on $\mathrm{AC}$ and $\mathrm{DC}$ Power Transmission, Birmingham, 2015, pp. 1-9.

[81] "Raetselhafte lokomotivstoerungen im raum zuerich," Eisenbahn-Revue, vol. 5, p. 171, 1995.

[82] S. Meyer, M. J., "Netzstabilitaet in grosseren bahnnetzen," Schweiz. Eisenb.-Rev., vol. 7-8, pp. 312-317, 1999.

[83] Aeberhard, M., "Anforderungen and die eingangs-admittanz von umrichter-triebfahrzeugen," Swiss Federal Railways I-20005, 2009.

[84] Aeberhard, M., "Spezifikation fuer triebfahrzeugfrequenzgangmessungen," Swiss Federal Railways 47.10.002, 2007.

[85] J. C. Willems, "Dissipative dynamical systems part I: General theory," Arch. Ration. Mech. Anal., vol. 45, no. 5, pp. 321-351, 1972.

[86] Wereley, N. M., "Analysis and control of linear periodically time varying systems," Doctoral dissertation, Massachusetts Institute of Technology, Cambridge, MA, 1990.

[87] J. R. C. Orillaza and A. R. Wood, "Harmonic State-Space Model of a Controlled TCR," IEEE Trans. Power Deliv., vol. 28, no. 1, pp. 197-205, Jan. 2013.

[88] J. Lyu, X. Zhang, X. Cai, and M. Molinas, "Harmonic State-Space Based Small-Signal Impedance Modeling of Modular Multilevel Converter with Consideration of Internal Harmonic Dynamics," IEEE Trans. Power Electron., pp. 1-1, 2018.

[89] J. J. Rico, M. Madrigal, and E. Acha, "Dynamic harmonic evolution using the extended harmonic domain," IEEE Trans. Power Deliv., vol. 18, no. 2, pp. 587-594, 2003.

[90] J. J. Chavez and A. Ramirez, "Dynamic Harmonic Domain Modeling of Transients in Three-Phase Transmission Lines," IEEE Trans. Power Deliv., vol. 23, no. 4, pp. 2294-2301, Oct. 2008.

[91] J. J. Chavez, A. Ramirez, and V. Dinavahi, "Dynamic harmonic domain modelling of synchronous machine and transmission line interface," IET Gener. Transm. Distrib., vol. 5, no. 9, pp. 912-920, 2011.

[92] E. Karami, M. Madrigal, G. B. Gharehpetian, K. Rouzbehi, and P. Rodriguez, "Single-Phase Modeling Approach in Dynamic Harmonic Domain," IEEE Trans. Power Syst., vol. 33, no. 1, pp. 257-267, Jan. 2018.

[93] M. Esparza, J. Segundo-Ramírez, J. B. Kwon, X. Wang, and F. Blaabjerg, "Modeling of VSC-Based Power Systems in the Extended Harmonic Domain," IEEE Trans. Power Electron., vol. 32, no. 8, pp. 5907-5916, Aug. 2017.

[94] J. C. Hernández-Ramírez, J. Segundo, F. Martínez-Cárdenas, and E. Barocio, "Harmonic linear time invariant modeling of grid-connected parallel inverters-based microgrids," in 2017 IEEE International Autumn Meeting on Power, Electronics and Computing (ROPEC), 2017, pp. 1-6.

[95] U. Vargas, A. Ramirez, and G. C. Lazaroiu, "Flexible extended harmonic domain approach for transient state analysis of switched systems," Electr. Power Syst. Res., vol. 155, no. Supplement C, pp. 40-47, Feb. 2018.

[96] P. Moreno and A. Ramirez, "Implementation of the Numerical Laplace Transform: A Review," IEEE Trans. Power Deliv., vol. 23, no. 4, pp. 2599-2609, 2008.

[97] P. Gómez and F. A. Uribe, "The numerical Laplace transform: An accurate technique for analyzing electromagnetic transients on power system devices," Int. J. Electr. Power Energy Syst., vol. 31, no. 2-3, pp. 116-123, Feb. 2009.

[98] R. Nuricumbo-Guillén, P. Gómez, F. P. Espino-Cortés, and F. A. Uribe, "Accurate computation of transient profiles along multiconductor transmission systems by means of the numerical Laplace transform," IEEE Trans. Power Deliv., vol. 29, no. 5, pp. 2385-2393, Oct. 2014.

[99] G. Bilal, P. Gómez, R. Salcedo, J. M. Villanueva-Ramirez, "Electromagnetic transient studies of large distribution systems using frequency domain modeling methods and network reduction techniques," Int. J. Electr. Power Energy Syst., vol. 110, no. 1, pp. 11-20, Sep. 2019.

[100] A. Tavighi, J. R. Martí, V. A. Galván, and J. A. Gutierrez-Robles, "TimeWindow-Based Discrete-Time Fourier Series for Electromagnetic Transients in Power Systems," IEEE Trans. Power Deliv., vol. 33, no. 5, pp. 2551-2561, Oct. 2018

[101] P. Lopez and A. Ramirez, "Sample-reduced frequency-domain approach for transient and steady-state computation of switched networks," in 2016 North American Power Symposium (NAPS), 2016, pp. 1-6.

[102] B. Gustavsen and A. Semlyen, "Rational approximation of frequency domain responses by vector fitting," IEEE Trans. Power Deliv., vol. 14, no. 3, pp. 1052-1061, Jul. 1999.

[103] D. Deschrijver, M. Mrozowski, T. Dhaene, and D. D. Zutter, "Macromodeling of Multiport Systems Using a Fast Implementation of the Vector Fitting Method," IEEE Microw. Wirel. Compon. Lett., vol. 18, no. 6 , pp. 383-385, Jun. 2008

[104] B. Gustavsen, "Improving the pole relocating properties of vector fitting," IEEE Trans. Power Deliv., vol. 21, no. 3, pp. 1587-1592, Jul. 2006.

[105] M. Esparza and J. Segundo-Ramirez, "Optimal design of power electronics converters using the extended harmonic domain," in 2014
IEEE International Autumn Meeting on Power, Electronics and Computing (ROPEC), 2014, pp. 1-6.

[106] M. Esparza and J. Segundo-Ramírez, "An exact method for analysis and component design of grid connected VSC-based power devices," Int. J. Electr. Power Energy Syst., vol. 78, pp. 489-498, Jun. 2016.

[107] A. Ramirez, "Frequency-Domain Computation of Steady and Dynamic States Including Nonlinear Elements," IEEE Trans. Power Deliv., vol. 24, no. 3, pp. 1609-1615, 2009.

[108] J. Kwon, X. Wang, F. Blaabjerg, C. L. Bak, A. R. Wood, and N. R. Watson, "Linearized Modeling Methods of AC-DC Converters for an Accurate Frequency Response," IEEE J. Emerg. Sel. Top. Power Electron., vol. 5, no. 4, pp. 1526-1541, Dec. 2017.

[109] Y. Vernay and B. Gustavsen, "Application of frequency-dependent network equivalents for EMTP simulation of transformer inrush current in large networks," presented at the International Conf. on Power Systems Transients, Vancouver, Canada, 2013.

\section{BIOGRAPHIES}

Juan Segundo (M'10) was born in Michoacan, Mexico, in 1979. He received the M.Sc. degree from the CINVESTAV Guadalajara, Zapopan, Mexico, in 2004, and the Ph.D. degree from the Universidad Michoacana de San Nicolas de Hidalgo, Michoacán, México, in 2010, both in electrical power systems. Since 2010, he has been with the Universidad Autonoma de San Luis Potosi, San Luis Potosí, Mexico. His research interests include power system harmonic analysis, modeling, optimal design, and simulation.

Alejandro Bayo-Salas (S'14 M'19) was born in Barcelona, Spain, in 1986. He received the BSc and MSc in Electrical Engineering from the Technical University of Catalonia, in 2013, and the Ph.D. degree in electrical engineering from KU Leuven, in 2018. He developed his Ph.D. in Elia, the Belgian TSO, and ELECTA-KU Leuven, supported by a Marie Curie Fellowship grant by the European Commission under the MEDOW project. In 2018, he joined Vestas Wind $\mathrm{A} / \mathrm{S}$ as a power systems engineer. He is also involved in CIGRE working group activities. His research interests include grid integration of power electronics, power system stability, and harmonic studies.

Miguel Esparza was born in Durango, Mexico. He received the B.Sc. degree in electronic engineering from the Instituto Tecnologico de Durango, in 2006. He received the M.E and the Ph.D. degrees in electrical engineering from Universidad Autonoma de San Luis Potosi, México in 2013 and 2017, respectively. He is currently with Technologies Delee Mexico as Ph. D. Researcher. Dr. Esparza research interests are on the harmonic modeling and simulation of power electronic systems.

Jef Beerten (S'07-M'13) received the M.Sc. and Ph.D. degrees in electrical engineering from the University of Leuven (KU Leuven), Belgium, in 2008 and 2013, respectively. Currently, he is an assistant professor with KU Leuven and EnergyVille. In 2011, he was a visiting researcher at the Royal Institute of Technology (KTH), Stockholm, Sweden, for three months. From April 2014 until March 2015, he was a visiting postdoctoral researcher at the Norwegian University of Science and Technology (NTNU), Trondheim, Norway. Dr. Beerten was the first winner of the ABB Research Award in Honor of Hubertus von Gruenberg in 2016 and received the KBVE/SRBE Robert Sinave Award and the Prix Paul Caseau from the Institut de France - EDF Foundation for his $\mathrm{Ph} . \mathrm{D}$. thesis on modeling and control of DC grids. Dr. Beerten is an active member of both the IEEE and CIGRE. His research interests include future power system dynamics, modeling, and control.

Pablo Gómez (SM'14) was born in Zapopan, Mexico, in 1978. He received the B.Sc. degree in mechanical and electrical engineering from Autonomous University of Coahuila, Monclova, Mexico, in 1999, and the M.Sc. and Ph.D. degrees in electrical engineering from CINVESTAV, Guadalajara, Mexico in 2002 and 2005, respectively. From 2005 to 2014, he was a Full-Time professor with the Electrical Engineering Department of SEPI-ESIME Zacatenco, National Polytechnic Institute, Mexico City, Mexico. From 2008 to 2010, he was on postdoctoral leave at the Tandon School of Engineering of New York University (formerly Polytechnic Institute of New York University), Brooklyn, NY, USA. Currently, he is an Associate Professor with the Electrical and Computer Engineering Department of Western Michigan University, Kalamazoo, MI, USA. He is the Chair of the Task Force on Frequency Domain Methods for Electromagnetic Transient Studies of the IEEE Power and Energy Society since 2013. His research interests include modeling of power equipment, transient analysis of electrical components and networks, high voltage engineering, and design optimization of power components. 